\title{
A forward closed-loop virtual simulation system for milling process considering dynamics processing- machine interactions
}

\author{
Wanqun Chen ${ }^{1,2}$, Zhen Tong ${ }^{1 *}$, Dehong Huo ${ }^{3}$, Wenbin Zhong ${ }^{1}$, Xiangqian Jiang ${ }^{1}$ \\ ${ }^{1}$ EPSRC Future Metrology Hub, Centre for Precision Technologies, University of Huddersfield, \\ Huddersfield, HD1 3DH, UK \\ ${ }^{2}$ Center for Precision Engineering, Harbin Institute of Technology, Harbin 150001, P. R. China \\ ${ }^{3}$ School of Mechanical and Systems Engineering, Newcastle University, Newcastle upon Tyne, NE 1 \\ $7 R U, U K$ \\ *Corresponding author: Zhen Tong, E-mail: z.tong@hud.ac.uk Tel: +44 (0)1484 471284
}

\begin{abstract}
In this paper, a closed-loop virtual simulation system has been developed to simulate the milling process considering the interactions between manufacturing processes and machine tool dynamics. The system consists of cutting force module, machining stability module and surface generation module. The synchronous effects of the machining parameters, tool geometry parameters and the dynamic performance of the machine tool system are considered in the model and the instant machine dynamic motion error is compensated in the model as a feedback to correct the cutter trajectories. Instantaneous tool-workpiece contact status is used to calculate cutting force and the peak-to-peak cutting force plot is used to predict the machining stability in time domain under different depths of cut and cutting speeds. The envelope curve of the cutting tool is used to reconstruct the machined surface texture. Moreover, to verify the feasibility of the proposed system, micro milling experiments are conducted with results showing that the simulation system enables the effective prediction of micro milling process such as the cutting forces and machined surface quality. It can be potentially applied in production on processing parameters optimization and surface topography prediction.
\end{abstract}

Keywords: high-speed milling; cutting force; surface generation; machining dynamics; virtual simulation.

\section{Introduction}

Milling, one of the most common processing methods of high machining efficiency, has been widely used in industry for mechanical equipment manufacturing and mold processing [1-3]. However, due to its discontinuous cutting feature, process-machine interactions (PMI) have significant effects on the machining process. For example, the cutting force often varies evidently which might cause the chattering of machining process or even the early failure of cutting tools. In-depth understanding of PMI is of significance to improve the machining efficiency and to ensure the surface quality of the machined surface.

PMI have become a central research topic in production engineering within the last years, not only in academic research but also in industrial companies. The PMI of a machine tool system mainly depends on the selected machining parameters and it can 
be evaluated by monitoring the time evolution of cutting force or testing the machining stability. Therefore, in order to improve the machining efficiency of the machine tool system and obtain high quality machined surface, the machining parameters are required to be optimized to achieve efficient and stable machining.

Numerous researches have been carried out to understand the machining process, such as cutting force, machining stability, surface topography and roughness. Grossi et al. [4] developed a cutting force prediction model for high speed machining and investigated the cutting force coefficient at different spindle speeds. Considering the influence of cutter vibrations and cutter run-out, Wang et al. [5] proposed a cutting force prediction algorithm, evidently reducing the prediction error of cutting force by up to $30 \%$. Kang et al. [6] proposed an analytical mechanistic model for micro end milling to predict the cutting force, in which the effect of cutting-edge radius of micro tool is considered. Bao and Tansel [7] proposed an improved cutting force model for micro milling considering the effects of the trochoidal motion of the cutter. Montgomery and Altintas [8] studied cutting force and surface generation in peripheral milling, and proposed a model to predict the cutting force and surface finish under rigid or dynamic cutting conditions. Zhang et al. [9] proposed a cutting force model which includes an algorithm for the calculation of the variable entry and exit angles caused by tool run-out and tool deflection.

As one form of self-excited unstable vibration, chatter is easily generated in the machining process. Chatter vibration will lead to an increased cutting force, and thus reduce the tool life and even damage the machine tool system [10]. In order to avoid chatter vibrations, a pre-plan of the machining processes is usually performed to find the chatter-free cutting conditions with the aid of experienced stability diagram. To improve the accuracy of stability lobes diagram, several modelling methods have been developed to calculate machine tool system dynamic performance and to predict the surface generation. Altintas and Budak [11] proposed one frequency domain solution, and it could be applied in the machining processes in which the radial cutting depth is larger than a quarter of the cutter diameter. Altintas et al. [12] presented a unified frequency and discrete time domain chatter stability laws for milling. This law could be applied to reveal the dynamic process of the performance of the machine tool system with low radial cutting depth and small number of teeth. Minis and Yanushevsky [13] described the dynamics of the milling process through differential-difference equations with time-dependent periodic coefficients, and examined the system stability by using Fourier analysis and the basic properties of the parametric transfer functions of linear periodic systems. Insperger et al. [14] investigated the influence of runout on the milling chatter frequencies by using Floquet theory. To predict the surface quality, Liu et al. [15] proposed a floor surface-generation model considering the effects of minimum chip thickness, elastic recovery, and transverse vibration. Kouravand et al. [16] developed a surface roughness model for end-milling of micro-channel by using kinematic rules and transformation operators. Ehmann and Hong [17] developed a prediction method of surface topography generation based on the general machine tool kinematics model and the generalized model with deterministic and non-deterministic 
cutting tool geometries. Peigne et al. [18] proposed a 2.5-dimensional geometrical model for the time domain simulation of surface generation in end milling. Ryu et al. [19] studied the effects of tool run-out, tool-setting errors (such as tool tilting and eccentricity between tool center and spindle rotation center) on the roughness and texture generation on the end milled surfaces and the tool deflection caused by cutting forces was analyzed.

However, the focus of above studies is mainly on the single role of cutting force, machining stability, surface topography and roughness, or the interaction between any two factors. It's well known that cutting force could impose external stimulation on the machine tool system during the machining process which will result in the instantaneous variation of the depth of cut and change tool cutting trajectories. This will significantly degrade the machined surface topography.

For this reason, one closed-loop virtual simulation system for milling process which consists cutting force module, machining stability module and surface generation module, is developed in the present study. The coupled interactions among the dynamic performance of machine tool system, the dynamic cutting force, machining stability and machined surface are considered in the proposed virtual simulation system by forming a real-time feedback between each module.

The paper is organized as follows: Section 2 briefly describes the integrated simulation system. Section 3 introduces each module of the integrated simulation system. In Section 4, a case study for micro milling by using the proposed integrated simulation system is given, and the experimental results are compared with the simulation results. The main conclusions drawn in this paper are given in section 5.

\section{Integrated simulation system for milling}

The flowchart of the virtual simulation system for milling is shown in Fig. 1. The cutting tool parameters (diameter, number of teeth, tool geometry, material parameters), spindle runout and the machining parameters (feed per tooth, spindle speed, depth of cut) and workpiece material property parameters are used as input to predict the cutter trajectories. The initial cutting force is first calculated in the time domain by the cutting force module based on the instantaneous uncut chip thickness. The synchronous effects of the machining parameters, tool geometry parameters and the dynamic performance of the machine tool system are considered in the model when updating the cutter trajectories and the instant machine dynamic motion error $\left(x_{t w}, y_{t w}\right)$ is compensated in the model as a feedback to correct the instantaneous uncut chip thickness. The output of cutting force and machine tool dynamic motion are used as the indicators to predict machining stability and to understand the surface generation process. The envelope curve of the cutting tool is used to predict the machined surface texture. Thus, a closedloop virtual simulation system is developed for the milling process which consists of cutting force module, machining stability module and surface generation module. 


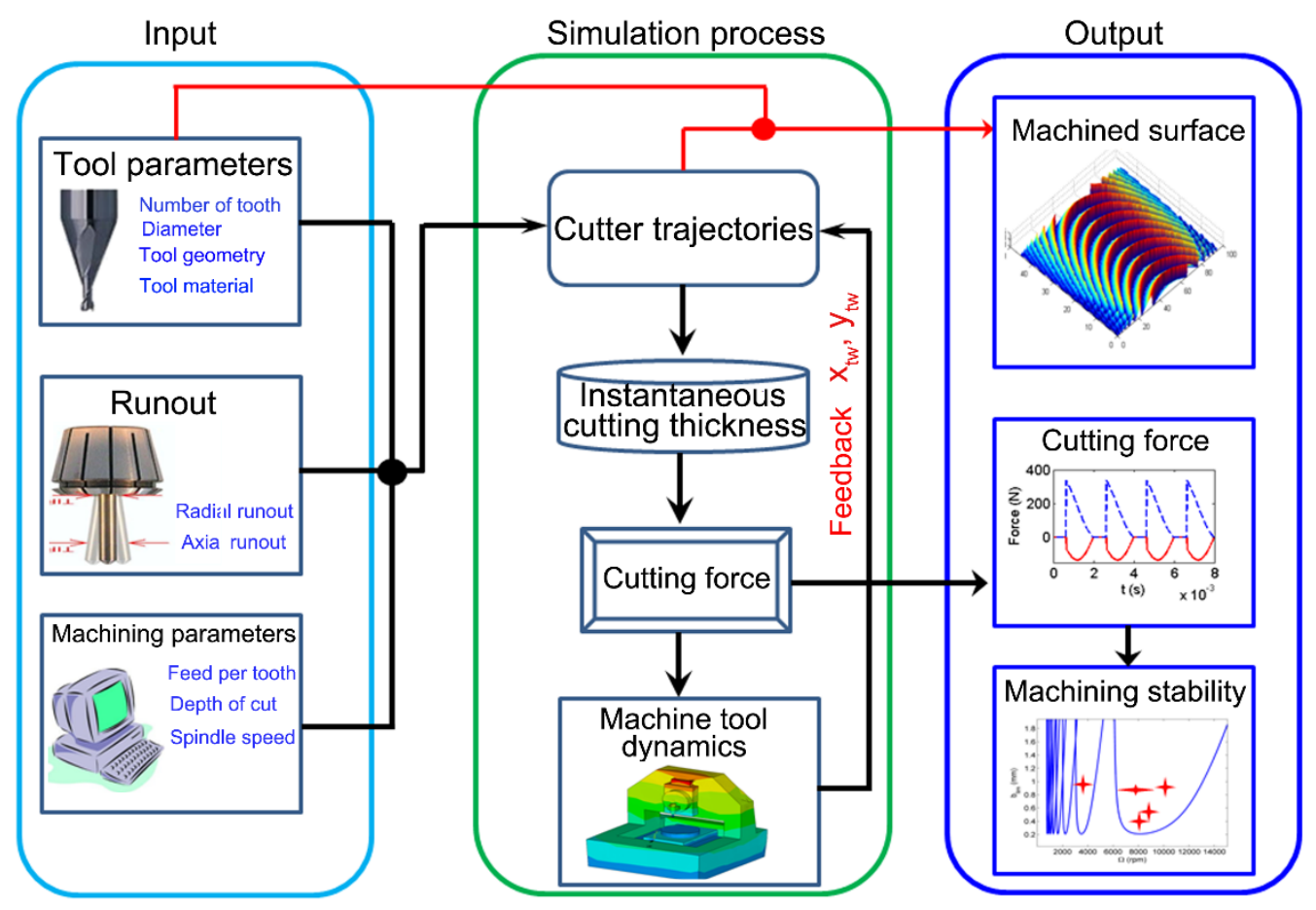

Fig.1 Scheme of integrated simulation system of milling

Considering the dynamic performance of the machine tool has significant influences on the dynamic cutting force, machining stability and surface quality of the machined surface, [20] an effective way is adopted to improve the simulation accuracy by considering the possible effects of machine tool system dynamics and multiple time delay in the machining process.

The simulation system structure is illustrated in Fig. 2. In the simulation process, the dynamic parameters of the machine system were firstly tested and pre-defined in the integrated simulation system. The dynamic performance of the machine tool system can be obtained by either machining experiments or finite element simulations[21]. The modal parameters of the machine tool system were obtained from frequency response function by the modal fitting technology. The machining parameters and cutter parameters were then input into the integrated simulation system. During the simulation process, the cutting force, dynamic tool path and the machining stability were calculated, and the machined surface topography was generated in the dynamic surface generation program by combining the cutter geometric parameters and dynamic tool cutting path. 


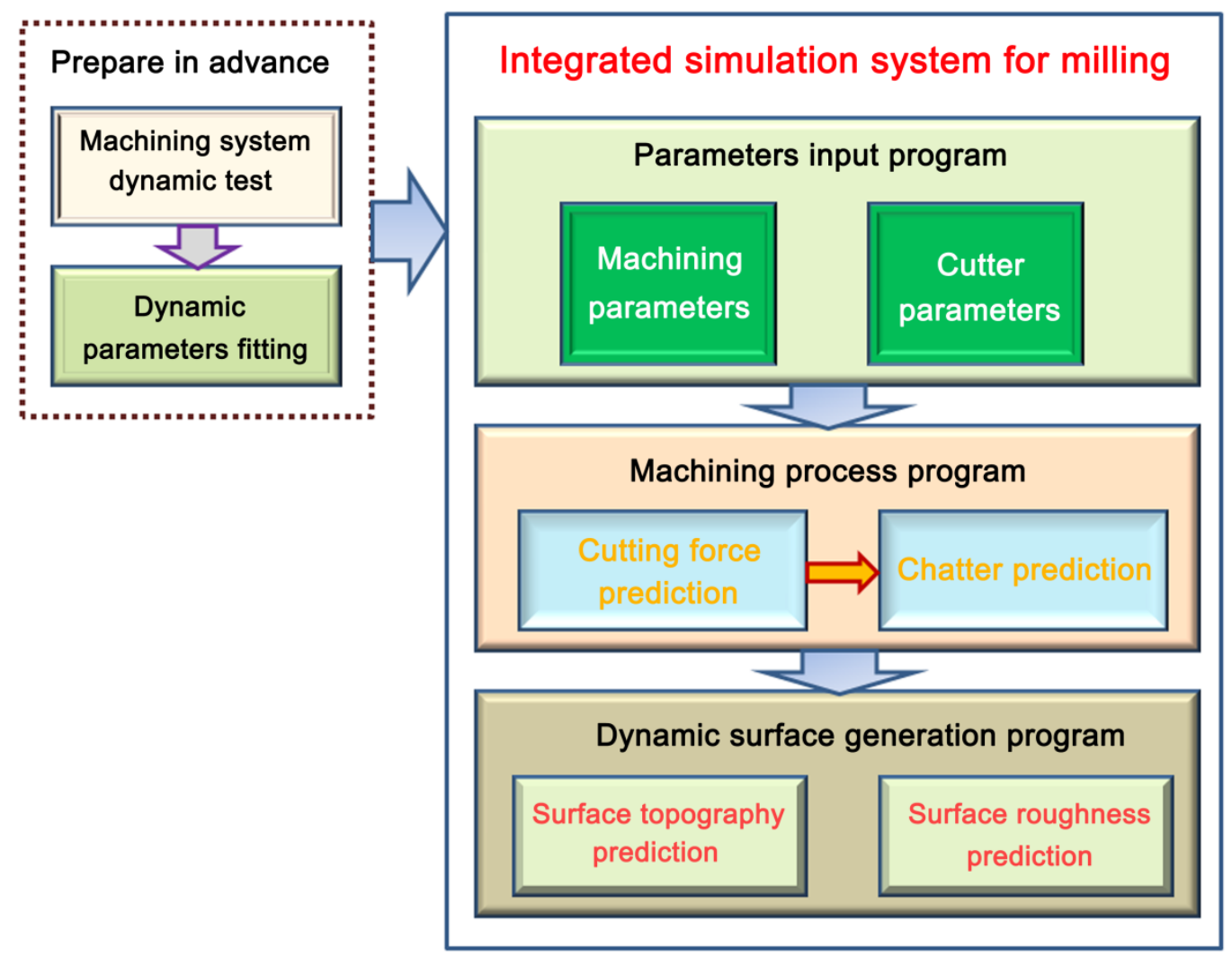

Fig.2 Structure of the proposed simulation system

\subsection{Cutting force module}

In most of the existing cutting force models, the calculation of the instantaneous uncut chip thickness is entirely based on input parameters, and pre-defined entrance and exit angles [22]. Cutting coefficients can be determined by either mechanistic or numerical methods, in this paper the value of $750 \mathrm{~N} / \mathrm{mm}^{2}$ is used for Al6061 [23]. However, in a milling process, the chip thickness and the cutting force tend to change nonlinearly, which results in dynamic fluctuations in the machining process. Moreover, the tool tooth may occasionally lose contact with workpiece in the cutting region, which could also induce the nonlinear fluctuation of cutting force [24]. For example, the cutting force could cause the deformation of the cutter and workpiece, which changes the instantaneous uncut chip thickness. The realistic cutting force of each tool tooth can also be affected by the feed per tooth, the deflection of the cutter, and even the surface topography/subsurface damage formed by previous teeth. Therefore, to accurately predict the cutting forces, the iterative approach is required, and a dynamic cutting force calculation scheme is proposed in the present cutting force module (as shown in Fig.3). 


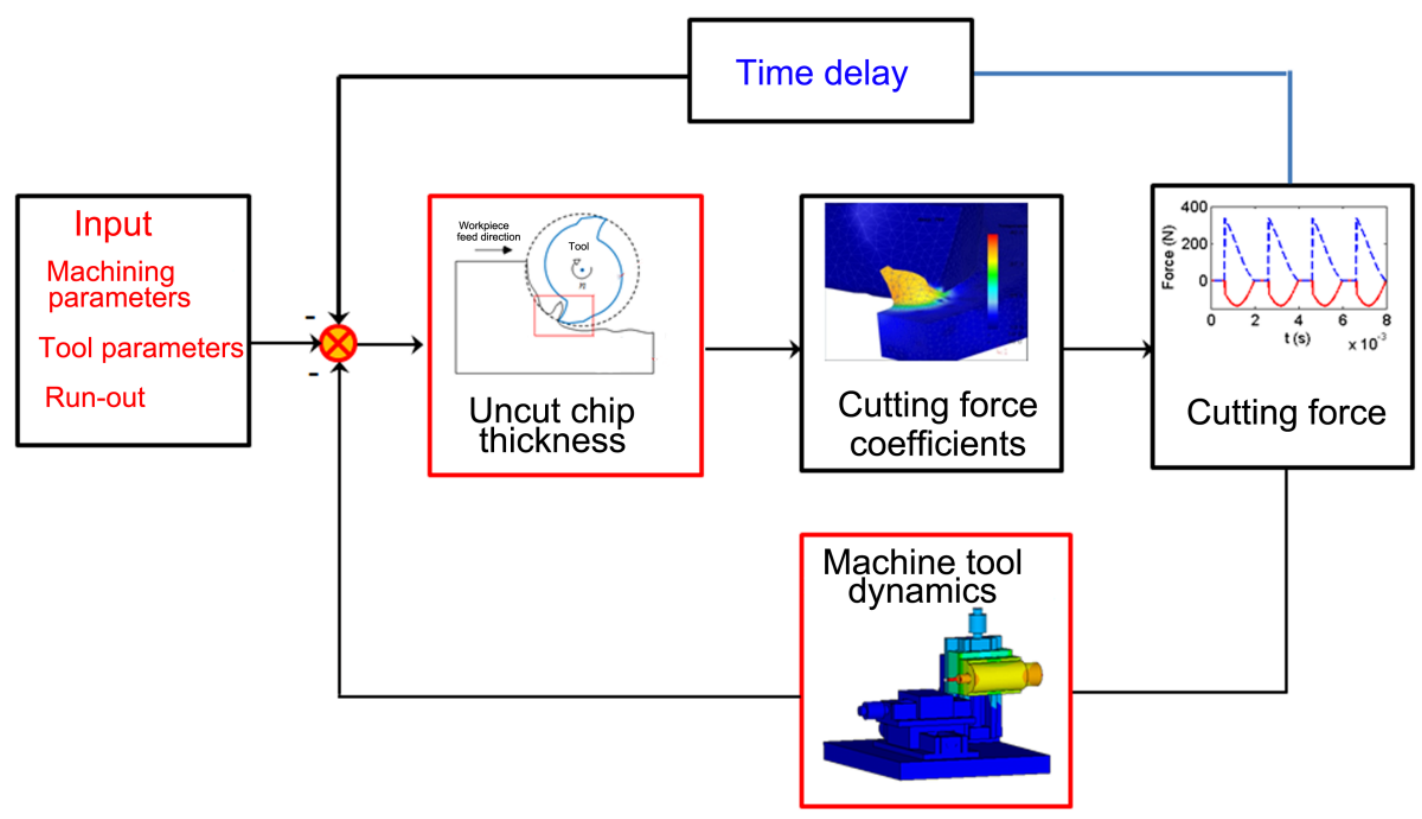

Fig.3 Dynamic cutting force calculation in time domain

In order to model the dynamic performance of the machine tool system, the structural loop of the machine tool is usually divided into a cutter-machine loop and a workpiecemachine loop. Since the dynamic performance of the cutter-machine loop is always worse than that of the workpiece-machine loop, therefore, only the cutter-machine loop is considered in this paper.

The cutter-machine loop can be simplified into two single degree of freedom (SDOF) systems in $x$ (feed direction) and $y$ (cross-feed direction). The equations of motion are depicted as:

$$
\left\{\begin{array}{l}
\mathrm{m}_{\mathrm{x}} \ddot{\mathrm{x}}(\mathrm{t})+\mathrm{c}_{\mathrm{x}} \dot{\mathrm{x}}(\mathrm{t})+\mathrm{k}_{\mathrm{x}} \mathrm{x}(\mathrm{t})=\mathrm{F}_{\mathrm{x}}(\mathrm{t}) \\
\mathrm{m}_{\mathrm{y}} \ddot{\mathrm{y}}(\mathrm{t})+\mathrm{c}_{\mathrm{y}} \dot{\mathrm{y}}(\mathrm{t})+\mathrm{k}_{\mathrm{y}} \mathrm{y}(\mathrm{t})=\mathrm{F}_{\mathrm{y}}(\mathrm{t})
\end{array}\right.
$$

where $m_{x}, m_{y}, c_{x}, c_{y}$ and $k_{x}, k_{y}$ are mass, damping, stiffness of the machine tool in $x$ and $y$ direction, respectively. $F_{x}(t)$ and $F_{y}(t)$ represent the instantaneous cutting forces in $x$ and $y$ direction, respectively. $x, y, \dot{x}, \dot{y}$, and $\ddot{x}, \ddot{y}$ are the positions, velocities and acceleration of the cutter in $x$ and $y$ directions.

After the solution of Euler integration, the Eq. (1) could be transformed into the following equations:

$$
\begin{array}{r}
\left\{\begin{array}{l}
\ddot{x}_{t}(t)=\frac{F_{x}(t)-c_{x} \dot{x}_{t}(t)-k_{x} x_{t}(t)}{m_{x}} \\
\ddot{y}_{t}(t)=\frac{F_{y}(t)-c_{y} \dot{y}_{t}(t)-k_{y} y_{t}(t)}{m_{y t}}
\end{array}\right. \\
\left\{\begin{array}{l}
\dot{x}_{t+1}(t)=\dot{x}_{t}(t)+\ddot{x}_{t}(t) d t \\
\dot{y}_{t+1}(t)=\dot{y}_{t}(t)+\ddot{y}_{t}(t) d t
\end{array}\right.
\end{array}
$$




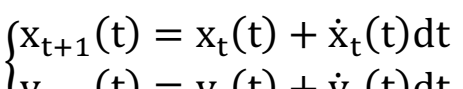

Where, the velocities on the right hand side of the equation in Eq.(3) are retained from the previous time step. The new velocities are then applied to determine the new displacements in Eq. (4). Again, the displacements on the right hand side of Eq.(4) are those from the previous time step. $d t$ is the time interval set by the program.

The relative dynamic displacement between the tool and workpiece in $x$ and $y$ direction can be given as:

$\left\{\begin{array}{l}x_{t w}(t)=x_{t}(t)-x_{w}(t) \\ y_{t w}(t)=y_{t}(t)-y_{w}(t)\end{array}\right.$

Thus, the instantaneous depth of cut can be obtained by combining the tool-workpiece displacement (calculated by Eq.(5)) and the specified depth of cut. The cutting force can then be calculated. More detailed description can be found in Ref. [25].

\subsection{Machining chatter module}

In time domain, the gradients information of cutting forces (peak to peak (PTP) force curves) can be used to evaluate the machining stability of a machine tool system [10]. The sharp change of the PTP force curve gradient indicates the transition of machining stability from stable to unstable (chatter) [26]. However, the PTP force curves could not give a direct representation of the relationship among machining stability, axial depthof-cut and spindle speed. For this reason, the gradients of the PTP force is calculated using the contour plot function in MATLAB and an analytical PTP stability lobes can be generated which clearly describe the machining status.

\subsection{Surface generation module}

The procedure of the surface generation is illustrated in Fig.4. The cutter geometry parameters were obtained through the SEM or AFM measurement of the tool cutting edges (step 1). In the milling process, the cutter is fed at specified machining path according the machining program to milling the workpiece into designed shape, and the machined surface can be generally expressed as the envelope curve of cutting tool motion trajectories (step 2). The whole machining process could be simulated by using the homogeneous transformation matrix (HTM). The Z-map technology in the commercial software MATLAB was then used to plot minimum $z$ position value against $x$ and $y$ position in the workpiece coordinate system (step 3), and then the final machined surface was reconstructed (step 4), the detail of the surface generation can be found in Ref.[27, 28] .

It is worth mention that the milling machine is not an ideal rigid body system, and the tool run-out during the machining process could lead to the dynamic fluctuation of the relative displacement between tool and workpiece, leading to the change of the processing trajectory. To accurately simulate the milling process, those motion errors caused by the spindle runout and tool alignment error could not be neglected. In the 
present surface generation module, the effects of the tool run-out and the dynamic response of the machining system on the surface generation were considered. The dynamic response of the machining system mainly refers to the dynamic displacement between tool and workpiece acting with the cutting force obtained from the cutting force module. The dynamic spindle run-out was treated as the results of the coupled effects of tool motion errors considering the tool alignment error and spindle runout. All these effects are considered as compensations on the tool position when updating the instantaneous tool cutting path.
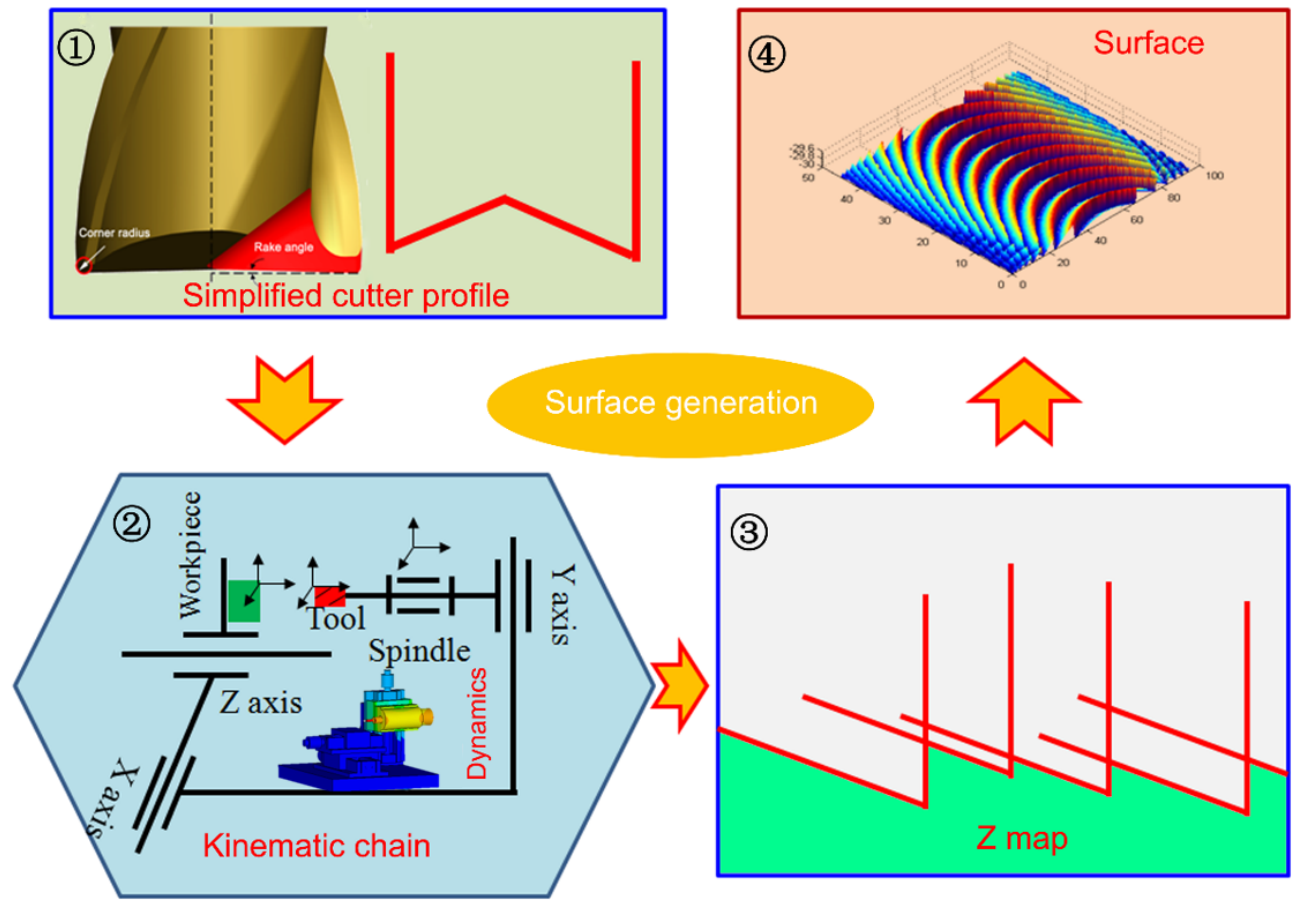

Fig.4 Scheme of surface generation module

\section{Case study: a micro milling process}

\subsection{Experimental setup}

To validate the feasibility of the proposed simulation system, a serial of slot milling experiments was conducted. The milling experiments were carried out on 3-axis precision milling machine tool (NANOWAVE MTS5R). The machine tool is equipped with three DC servo motors-driven precision linear stages with smallest feed of $0.1 \mu \mathrm{m}$, and a high-speed spindle with adjustable rotation speed range from 5,000 rpm to 80,000 $\mathrm{rpm}$, the tool runout in the whole rotation range is less than $1 \mu \mathrm{m}$. The practical experimental setup is illustrated in Fig. 5. A 3-component piezoelectric dynamometer (Kistler $9256 \mathrm{C} 2$, with the sampling frequency up to $3.5 \mathrm{kHz}$ ) is mounted on the $\mathrm{X}-\mathrm{Z}$ stage to measure the feed and cross-feed cutting forces. The workpiece material is Al6061, the workpiece is clamped on a fixture attached to the dynamometer. 


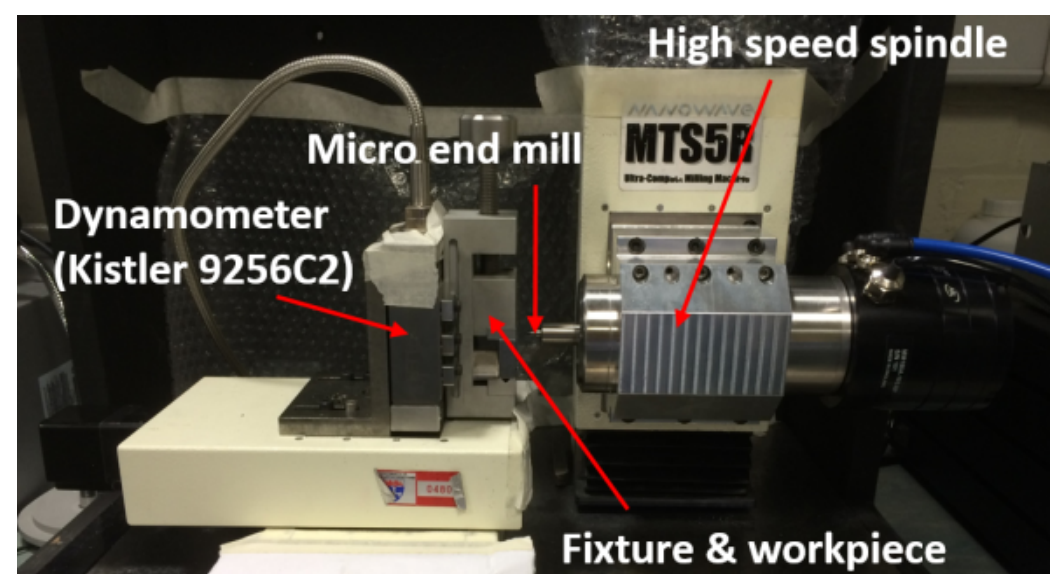

Fig. 5 Machine tool system and experimental setup

\subsection{Simulation parameters}

The dynamic performance of the machine tool is an important input in the simulation and should be obtained beforehand. Due to the small diameter $(1 \mathrm{~mm})$ of the cutting tool, it is difficult to experimentally detect the dynamic response of the tool tip. Therefore, finite element simulations are adopted in this case. Fig.6 (a) shows the finite element model for the micro milling machine. The key input parameters of the machine tool components, such as bearing stiffness, materials properties, damping coefficients, are extracted from relevant datasheet and/or determined from dynamic tests, the details can be found in Ref[28]. The joint characteristics of the machine tool, such as the bolt joint and the bearing connection have great impact on the dynamic performance. Therefore, the modeling approach of the junction directly determines the accuracy of the whole model of the machine tool. In this study, the contact elements CONTA173 and TARGE170 were applied to the contact components. The contact rolling bearings in the slides were modelled by spring elements. The Prets 179 element was used to simulate the bolt joint which can exert the preload by the node K. A modal analysis was first performed to obtain the natural frequencies of machine tool and the corresponding vibration modes. As shown in Fig.6 (b), the $1^{\text {st }}$ order natural frequency of the machine system is $478 \mathrm{~Hz}$ and its vibration mode is the spindle swinging around Y-axis with the Y slide. By using the peak-picking fitting method, the modal dynamic parameters can be determined. 


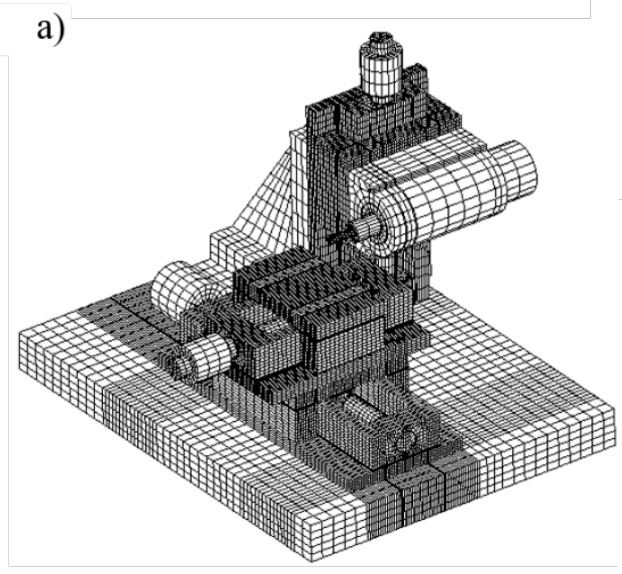

b)

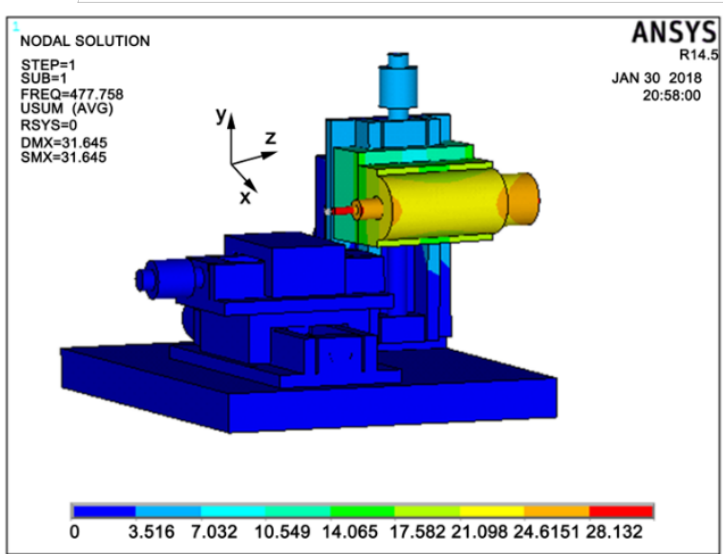

Fig. 6 Finite element model of the micro milling machine system (a) finite element model for the micro milling machine; (b) $1^{\text {st }}$ order natural frequency of the machine system.

Two-flute micro flat end mills with the cemented carbide is adopted in the machining experiments. Table 1 lists the detailed parameters used in milling experiments, including tool geometry parameters, dynamic parameters of the machine tool and machining parameters. Those parameters were directly used as the boundary conditions of the simulation system to stimulate the milling process. Two set machining parameters with different spindle speed of $18,000 \mathrm{rpm}$ and $26,000 \mathrm{rpm}$ were selected to demonstrate the effectivity of the proposed simulation system (as shown in Table 2), and the feed per tooth and the depth of cut were specified as $10 \mu \mathrm{m}$ and $0.25 \mathrm{~mm}$, respectively. Although the slot milling is selected as the case study to verify the proposed system, the system is also effective for side milling.

Table 1 Tool geometry parameters and dynamic parameters of the machine tool

\begin{tabular}{|c|c|c|c|}
\hline \multicolumn{2}{|l|}{ Tool geometry parameters } & \multicolumn{2}{|c|}{ Dynamic parameters of the machine tool } \\
\hline \multirow{2}{*}{ Diameter $(\mathrm{mm})$} & \multirow{2}{*}{1} & \multirow{2}{*}{ Stiffness $(\mathrm{N} / \mathrm{mm})$} & $x: 2200$ \\
\hline & & & $y: 2650$ \\
\hline \multirow{2}{*}{ End cutting edge angle $\left(^{\circ}\right)$} & \multirow{2}{*}{5} & \multirow{3}{*}{$\operatorname{Mass}(\mathrm{Kg})$} & $x: 9.628$ \\
\hline & & & $v: 11.6$ \\
\hline Corner radius $(\mu m)$ & 3 & & \\
\hline \multirow{2}{*}{ Tooth number } & \multirow{2}{*}{2} & \multirow[t]{2}{*}{ Damping ratio } & \\
\hline & & & $y: 0.0156$ \\
\hline
\end{tabular}

Table 2 Machining parameters of slot milling

\begin{tabular}{|c|c|c|}
\hline \multicolumn{3}{|c|}{ Machining parameters } \\
\hline & $1^{\text {st }}$ set & $2^{\text {nd }}$ set \\
\hline Spindle speed (rpm) & 18,000 & 26,000 \\
\hline Feed per tooth $(\mu \mathrm{m})$ & 10 & 10 \\
\hline Cutting depth (mm) & 0.25 & 0.25 \\
\hline
\end{tabular}




\subsection{Results and discussion}

Step 1: The cutting force module was firstly run to obtain dynamic cutting forces. It will be adopted to further evaluate the machining stability of the machining system. Fig. 7 compares the cutting forces predicted by the simulation system and the cutting forces measured by the dynamometer in the $1^{\text {st }}$ set machining experiment. It shows that the simulation results accorded well with the experimental results and both the $x$ - and $y$ direction cutting forces fluctuate within a range of $4 \mathrm{~N}$. As compared with the $1^{\text {st }}$ set machining, the amplitude of cutting force of the $2^{\text {nd }}$ set machining increased to $20 \mathrm{~N}$ and $12 \mathrm{~N}$ in $x$ and $y$ direction, respectively (Fig. 8). High accordance between the simulation results and the experimental results were found for the $2^{\text {nd }}$ set machining as well, which demonstrated the effectivity of the cutting force prediction module. This accordance attributes to the consideration of the PMI effects on the machining process in the proposed cutting force model. This feature has great advantage than conventional cutting force models which didn't consider the dynamic performance of machine tool system. Moreover, the increase of the cutting forces for the $2^{\text {nd }}$ machining indicated that the cutting speed has significant effects on the machining process under the same depth of cut and the feed per tooth. The increase of the cutting forces might imply the alternation of the machining status from the stable to unstable, which will be further analyzed by the stability module.
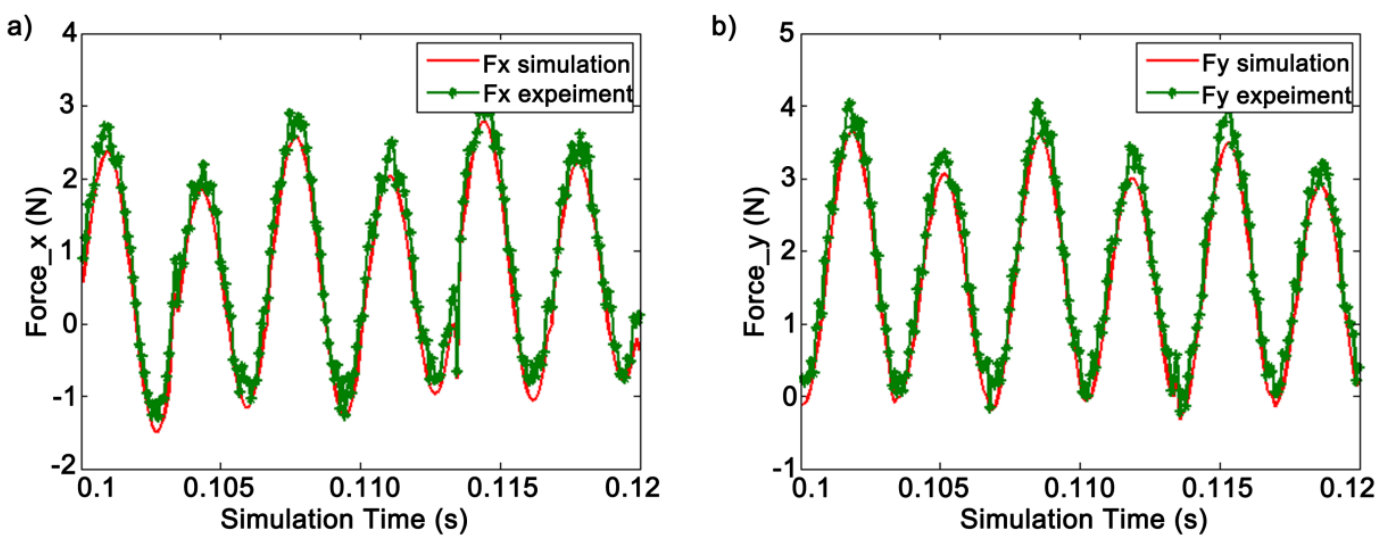

Fig. 7 Comparison of cutting force between the simulation results and experiments with $1^{\text {st }}$ set machining parameters. a) Force in $x$ direction; b) force in $y$ direction
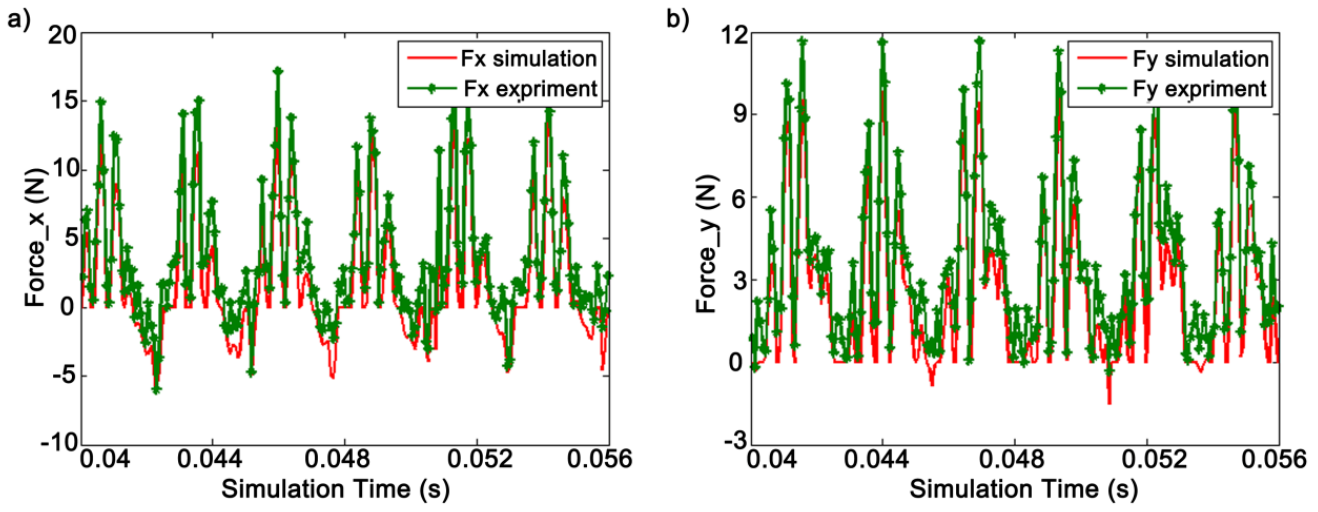
Fig. 8 Comparison of cutting force between the simulation results and experiments with $2^{\text {nd }}$ set machining parameters. (a) Force in $x$ direction; (b) force in $y$ direction

Step 2: Machining stability module

To further demonstrate the feasibility of using the system on processing parameters optimization, a machining stability diagrams was generated using the chatter module of the proposed simulation system. A large amount of simulations was running with the axial depth-of-cut changes from $0.1 \mathrm{~mm}$ to $1 \mathrm{~mm}$ at an interval of $0.1 \mathrm{~mm}$ (10 depths of cut) and the spindle speeds is chosen from 8,000 to 55,000 rpm with an interval of 235 rpm. The peak-to-peak (PTP) cutting force plot and the Peak-to-peak stability lobes are consist of the results obtained from 2000 simulation runs. As shown in the Fig.9 a), the cutting force is stable when the axial depth of cut is less than $0.1 \mathrm{~mm}$. With the increases of the axial depth of cut, the PTP Force_y is changing with the spindle speed and the chatter occurs. In order to reflect the relationship between cutting stability, axial depthof-cut and spindle speed, a contour plot of the PTP Force_y is further generated as shown in Fig.9 b). This diagram reflects the machining stability under different processing conditions. It can be found that the $1^{\text {st }}$ set machining parameters belongs to the stable region and the $2^{\text {nd }}$ set parameters will lead to the unstable machining.
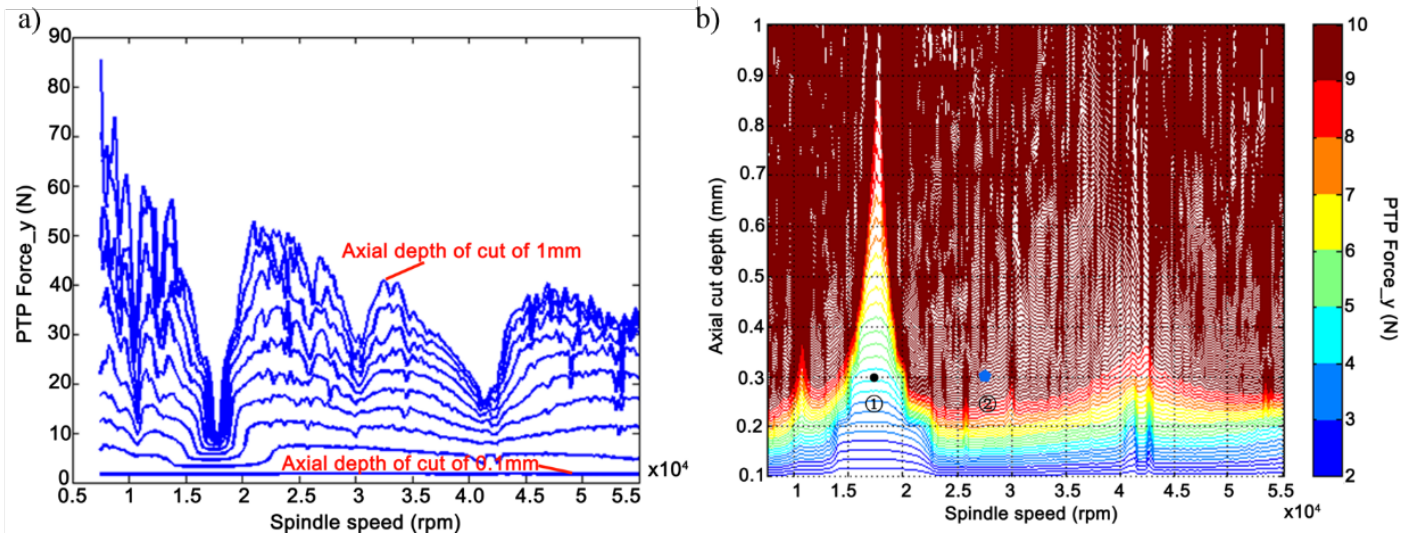

Fig.9 Stability prediction. (a) Peak-to-peak force plot; (b) Peak-to-peak stability lobes

For experimental verification, the fast Fourier transform (FFT) analysis of the experimental cutting forces obtained in step 1 was carried out. The FFT analysis results were shown in Fig.10. The results show that only the tooth passing frequency and its harmonic frequencies can be found for the $1^{\text {st }}$ machining (Fig.10 (a)), which indicates that no chatter occurs during the $1^{\text {st }}$ set machining process. For the $2^{\text {nd }}$ set machining parameters, the cutting force were found to fluctuate violently. Indeed, the cutting-in and cutting-out of the milling tool could lead to the instability of the machining process. The FFT analysis result shows that except the tooth pass frequency and its harmonic frequencies, chatter frequencies were also observed as indicated in Fig.10 b). Thus, the chatter occurs during the $2^{\text {nd }}$ machining process. The experimental results agreed with the simulation prediction, which demonstrates the effectivity of using the machining stability module to predict the machining status. 
a)

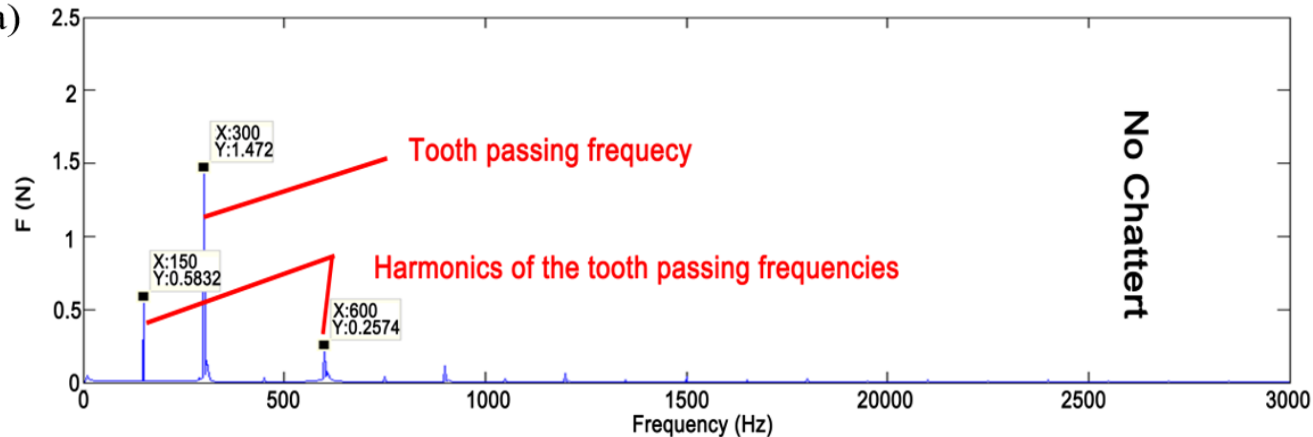

b)

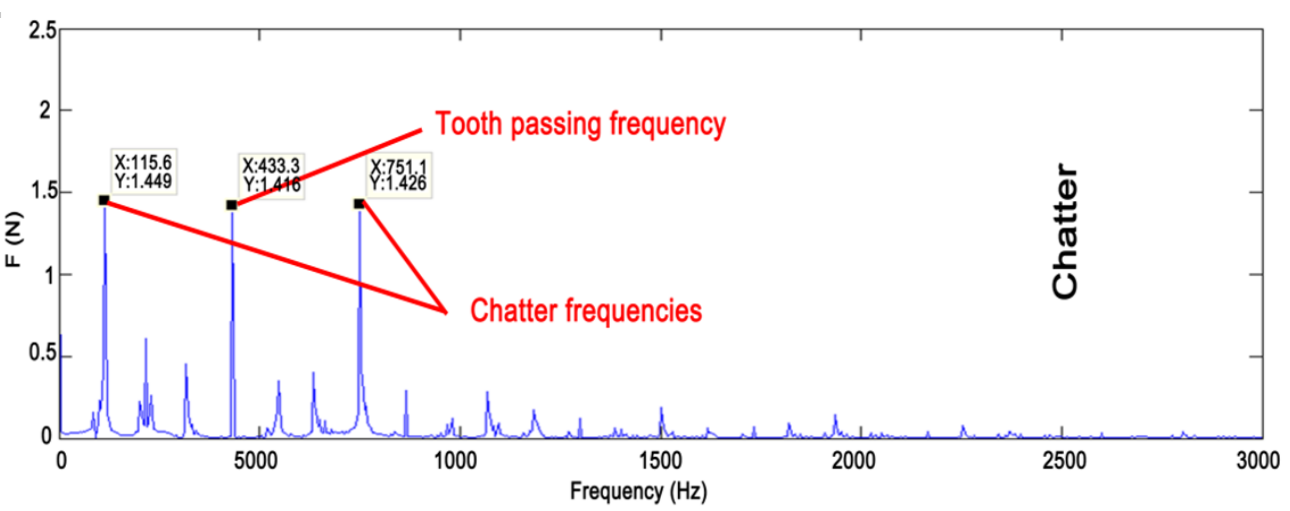

Fig. 10 The experimental results of machining stability. (a) FFT of the cutting force of $1^{\text {st }}$; (b) FFT of the cutting force of $2^{\text {nd }}$.

Step 3 Surface topography and roughness generation

In the surface generation module, the tool profile (expressed in a mathematical model) and the tool trajectories considering the dynamic displacement caused by the cutting force are combined and used to reconstruct the 3D surface topography. Figs. 11 and 12 show the simulation predicted surface topographies of the machined surfaces under the two sets of machining parameters, respectively. For the $1^{\text {st }}$ machining case, it can be found that the trajectory of the tool tip exhibits evident periodicity (Fig.11 a) and clear and regular tool marks can be found on the machined surface (Fig.11 b), indicating that the machining process is stable. The surface roughness was calculated according ISO 4287:1997 standard, the predicted surface roughness $(\mathrm{Ra})$ is $0.18 \mu \mathrm{m}$.

For the $2^{\text {nd }}$ machining case, it is observed that the periodicity of tool trajectory (Fig.12 a) is obviously worse than that of the $1^{\text {st }}$ case and the tool marks on the machined surface is messy (Fig. 12 b). The predicted surface roughness $(\mathrm{Ra})$ is $0.536 \mu \mathrm{m}$, much worse than that of the $1^{\text {st }}$ cutting. The results also indicate that the machining process is instable under the $2^{\text {nd }}$ set machining parameters. 
a)

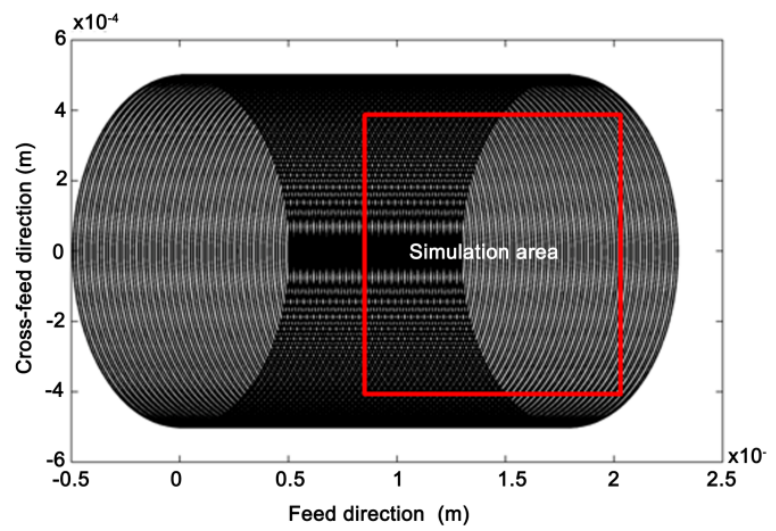

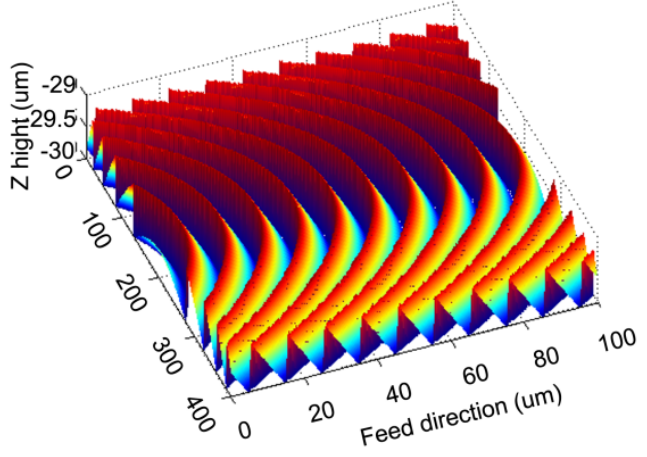

Fig.11 Simulation results of $1^{\text {st }}$ set machining parameters. (a) Tool trajectory; (b) Predicted surface

a)

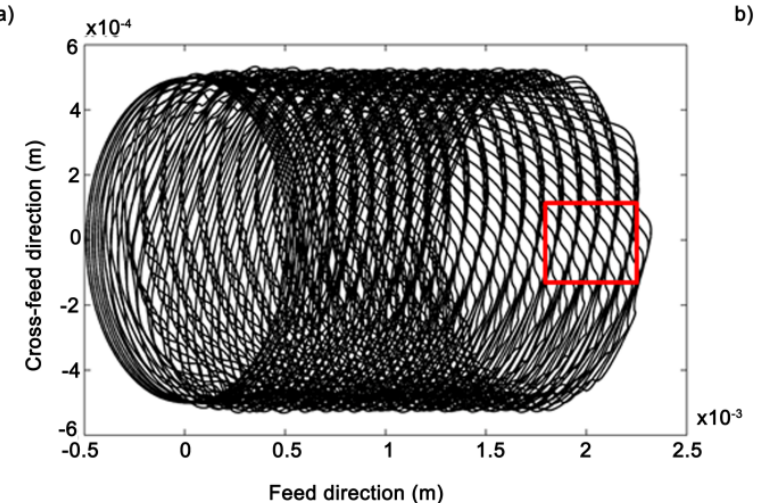

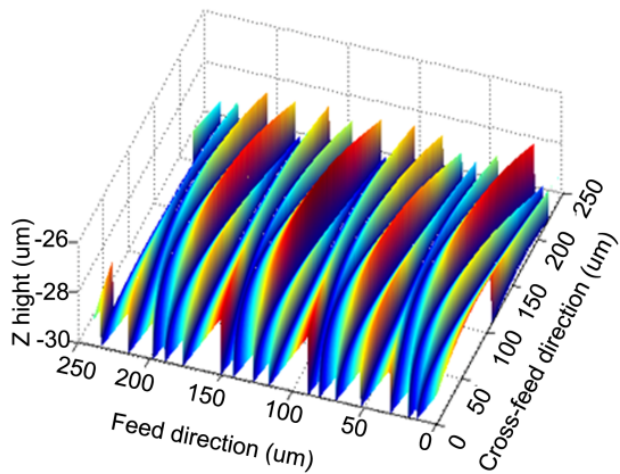

Fig. 12 Simulation results of $2^{\text {nd }}$ set machining parameters. (a) Tool trajectory; (b) Predicted surface

To validate the simulation results, experiments were carried out using the same machining parameters. Figs. 13 and 14 are the surface measurement results obtained by a white light interferometer (Vecco NT1100). As shown in Fig.13, regular tool marks can be found in the machined surface when machining at the spindle speed of 18,000 $\mathrm{rpm}$, indicating that a stable machining process was achieved under the $1^{\text {st }}$ set of machining parameters. The surface roughness $(\mathrm{Ra})$ is $0.190 \mu \mathrm{m}$, approximately consistent with the value of $0.180 \mu \mathrm{m}$ predicted by simulation.

For the $2^{\text {nd }}$ machining, the spindle speed was increased to $26,000 \mathrm{rpm}$, and the tool marks on the machined surface are found to be orderless as shown in Fig.14. The surface roughness $(\mathrm{Ra})$ of machined surface is $0.518 \mu \mathrm{m}$ which agreed well with the value of $0.536 \mu \mathrm{m}$ predicted by simulation model. It is noted that the $10 \sim 20 \mathrm{~nm}$ difference on the surface roughness between simulation and experimental results might result from the uncertainty of the measurement equipment and the possible random machining error of the experiments. 

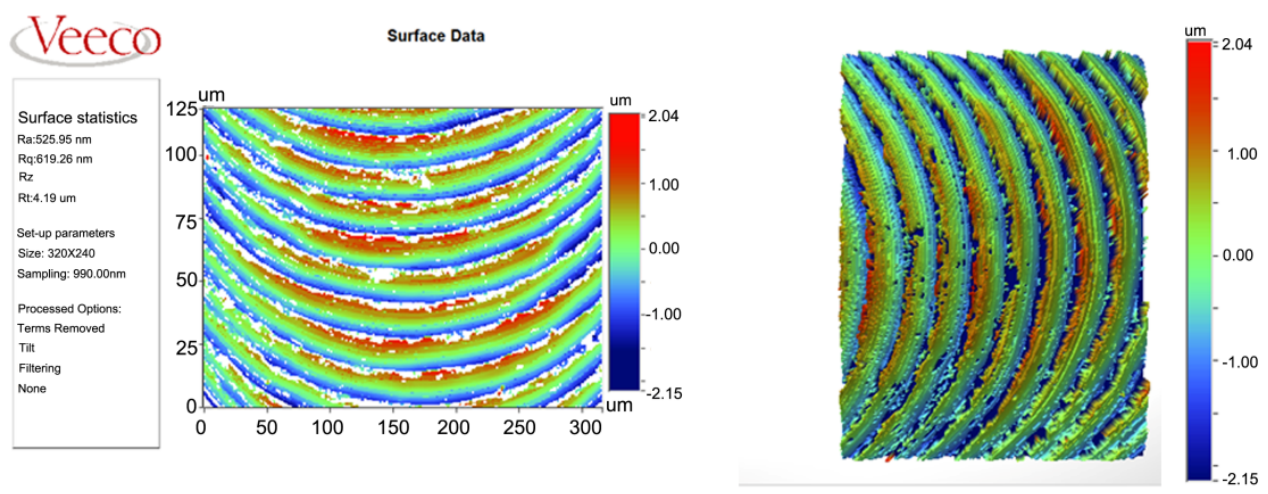

Fig. 13 Test results of $1^{\text {st }}$ set machining parameters
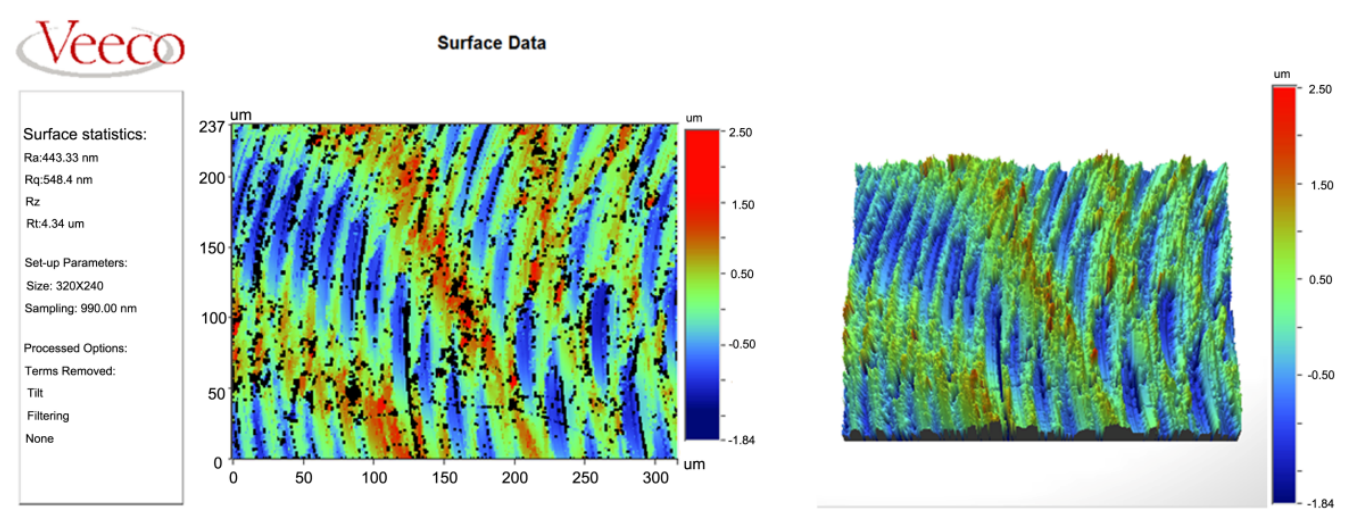

Fig. 14 Test results of $2^{\text {nd }}$ set machining parameters

The good agreement of the simulation and experimental results indicates the high accuracy and reliability of the proposed simulation system for micro milling process. It is also noted that the proposed simulation system can predict the cutting force, the machining stability and the machined surface topography in advanced with preset machining parameters, which potentially can reduce the cost and time on processing parameters selection and optimization in a production line.

\section{Conclusion}

The paper presents a novel simulation system to simulate the surface generation in milling process. The feasibility of the simulation system has been demonstrated by experiments. The interactions between structure and process in the machining process is established and a basic understanding of the acting inter-relationships is achieved, which can be used to specifically influence and plan manufacturing processes in the future. The conclusions are drawn as followings:

1) A forward closed-loop model for the milling process is established considering the dynamics processing-machine interactions. The proposed system can be used to predict the cutting force, machining stability, and machined surface topography under different processing parameters. 
2) A time domain cutting force module considering the dynamic regenerative effect has been established and a machining chatter prediction module based on the changes of PTP force has been achieved. The proposed model successfully predicted the occurrence of chatter and the simulation results have been verified by the experimental results.

3) The fluctuation of cutting forces and the dynamic performance of the machine have significant effects on the machined surface topography. The proposed surface simulation method bridges the gap between surface topography prediction and the dynamics processing-machine interactions. The machined surface roughness can be predicted by the proposed model.

4) The good consistence of simulation and experimental results indicate that the proposed system can effectively predict the typical phenomena of a milling process. This method can be potentially applied to the selection and optimization of machining parameters in production.

\section{Acknowledgment}

The authors gratefully acknowledge financial sup- port of the National Natural Science Foundation of China (Grant No. 499 51505107), the UK Engineering and Physical Sciences Research Council (EP/I033424/1, EP/M020657/1), the Project (HIT.NSRIF.2017029) Supported by the Natural Scientific Research Innovation Foundation in Harbin Institute of Technology, and the European Union's Horizon 2020 research and innovation programme under grant agreement No. 767589.

\section{Conflict of interest}

The authors declare that there is no conflict of interest.

\section{Reference:}

[1] Weule, H., V. Hüntrup, and H. Tritschler. "Micro-cutting of steel to meet new requirements in miniaturization." CIRP Annals 50, no. 1 (2001): 61-64.

[2] Liu, X., R. E. DeVor, Shiv Gopal Kapoor, and K. F. Ehmann. "The mechanics of machining at the microscale: assessment of the current state of the science." Journal of manufacturing science and engineering 126, no. 4 (2004): 666-678.

[3] Alting, Leo, F. Kimura, Hans Nørgaard Hansen, and Giuliano Bissacco. "Micro engineering." CIRP Annals 52, no. 2 (2003): 635-657.

[4] Grossi, N., L. Sallese, A. Scippa, and G. Campatelli. "Speed-varying cutting force coefficient identification in milling." Precision Engineering 42 (2015): 321-334.

[5] Wang, S. B., L. Geng, Y. F. Zhang, K. Liu, and T. E. Ng. "Cutting force prediction for five-axis ball-end milling considering cutter vibrations and run-out." International Journal of Mechanical Sciences 96 (2015): 206-215.

[6] Kang, I. S., J. S. Kim, J. H. Kim, M. C. Kang, and Y. W. Seo. "A mechanistic model of cutting force in the micro end milling process." Journal of Materials Processing Technology 187 (2007): 250-255. 
[7] Bao, W. Y., and I. N. Tansel. "Modeling micro-end-milling operations. Part I: analytical cutting force model." International Journal of Machine Tools and Manufacture 40, no. 15 (2000): 2155-2173.

[8] Montgomery, D., and Y. Altintas. "Mechanism of cutting force and surface generation in dynamic milling." Journal of engineering for industry 113, no. 2 (1991): 160-168.

[9] Zhang, Xuewei, Kornel F. Ehmann, Tianbiao Yu, and Wanshan Wang. "Cutting forces in micro-end-milling processes." International Journal of Machine Tools and Manufacture 107 (2016): 21-40.

[10] Smith, S., and J. Tlusty. "Efficient simulation programs for chatter in milling." CIRP annals 42, no. 1 (1993): 463-466.

[11] Altintaş, Y., and E. Budak. "Analytical prediction of stability lobes in milling." CIRP annals 44, no. 1 (1995): 357-362.

[12] Altintas, Y., Gábor Stépán, D. Merdol, and Zoltán Dombóvári. "Chatter stability of milling in frequency and discrete time domain." CIRP Journal of Manufacturing Science and Technology 1, no. 1 (2008): 35-44.

[13] Minis, I., and R. Yanushevsky. "A new theoretical approach for the prediction of machine tool chatter in milling." Journal of Engineering for Industry 115, no. 1 (1993): 1-8.

[14]Insperger, Tamás, Brian P. Mann, Tobias Surmann, and Gábor Stépán. "On the chatter frequencies of milling processes with runout." International Journal of Machine Tools and Manufacture 48, no. 10 (2008): 1081-1089.

[15]Liu, Xinyu, Richard E. DeVor, and Shiv G. Kapoor. "Model-based analysis of the surface generation in microendmilling-Part I: Model development." Journal of manufacturing science and engineering 129, no. 3 (2007): 453-460.

[16]Kouravand S, Imani B M. Developing a surface roughness model for end-milling of micro-channel[J]. Machining Science and Technology, 2014, 18(2): 299-321.

[17]Ehmann, K. F., and M. S. Hong. "A generalized model of the surface generation process in metal cutting." CIRP annals 43, no. 1 (1994): 483-486.

[18] Peigne, G., H. Paris, and D. Brissaud. "A model of milled surface generation for time domain simulation of high-speed cutting." Proceedings of the Institution of Mechanical Engineers, Part B: Journal of Engineering Manufacture 217, no. 7 (2003): 919-930.

[19]Ryu, Shi Hyoung, Deok Ki Choi, and Chong Nam Chu. "Roughness and texture generation on end milled surfaces." International Journal of Machine Tools and Manufacture 46, no. 3-4 (2006): 404-412.

[20]Huo, Dehong, Wanqun Chen, Xiangyu Teng, Chao Lin, and Kai Yang. "Modeling the influence of tool deflection on cutting force and surface generation in micromilling." Micromachines 8, no. 6 (2017): 188.

[21]Cheng, K. ed., 2008. Machining dynamics: fundamentals, applications and practices. Springer Science \& Business Media.

[22]Doukas, C., Pandremenos, J., Stavropoulos, P., Foteinopoulos, P. and Chryssolouris, G., 2012. On an empirical investigation of the structural behavior of robots. Procedia CIRP, 3, pp.501-506. 
[23] Tlusty, G., 2000. Manufacturing equipment and processes. Prentice-Hall, Upper Saddle River, NJ.

[24] Tlusty, J., and F. Ismail. "Basic non-linearity in machining chatter." CIRP Annals 30, no. 1 (1981): 299-304.

[25]Chen, Wanqun, Xiangyu Teng, Dehong Huo, and Quanlong Wang. "An improved cutting force model for micro milling considering machining dynamics." The International Journal of Advanced Manufacturing Technology 93, no. 9-12 (2017): 3005-3016.

[26] Smith, S., and J. Tlusty. "An overview of modeling and simulation of the milling process." Journal of engineering for industry 113.2 (1991): 169-175. 